\title{
Speech fluency in acquired apraxia of speech during narrative discourse: Group comparisons and dual task effects
}

\author{
Tyson G. Harmon \\ Brigham Young University, tyson_harmon@byu.edu \\ Adam Jacks \\ University of North Carolina at Chapel Hill \\ Katarina L. Haley \\ University of North Carolina at Chapel Hill
}

Follow this and additional works at: https://scholarsarchive.byu.edu/facpub

Part of the Communication Sciences and Disorders Commons

\section{Original Publication Citation}

Harmon, T. G., Jacks, A., \& Haley, K. L. (2019). Speech fluency in acquired apraxia of speech during narrative discourse: Group comparisons and dual-task effects. American Journal of Speech-Langauge Pathology, 28(July), 905-914. https://doi.org/10.1044/2018_AJSLPMSC18-18-0107

\section{BYU ScholarsArchive Citation}

Harmon, Tyson G.; Jacks, Adam; and Haley, Katarina L., "Speech fluency in acquired apraxia of speech during narrative discourse: Group comparisons and dual task effects" (2018). Faculty Publications. 3251. https://scholarsarchive.byu.edu/facpub/3251

This Peer-Reviewed Article is brought to you for free and open access by BYU ScholarsArchive. It has been accepted for inclusion in Faculty Publications by an authorized administrator of BYU ScholarsArchive. For more information, please contact ellen_amatangelo@byu.edu. 
Speech fluency in acquired apraxia of speech during narrative discourse:

Group comparisons and dual task effects

\author{
Tyson G. Harmon ${ }^{\mathrm{a}}$ \\ Adam Jacks ${ }^{\mathrm{b}}$ \\ Katarina L. Haley
}

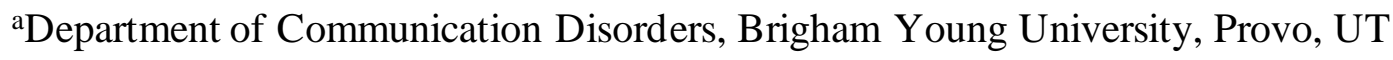

${ }^{b}$ Division of Speech and Hearing Sciences, Department of Allied Health Sciences, University of North Carolina, Chapel Hill, NC

RUNNING HEAD: SPEECH FLUENCY IN APRAXIA OF SPEECH

Please address correspondence to:

Tyson G. Harmon

Department of Communication Disorders

158 John Taylor Building

Brigham Young University

Email: Tyson_Harmon@ byu.edu

Telephone: 801-422-1251

Keywords: aphasia, apraxia of speech, cognition, stroke, fluency, speech production 


\begin{abstract}
Purpose: Slowed speech and interruptions to the flow of connected speech are common in aphasia. These features are also observed during dual task performance for neurotypical adults. The purposes of this study were to determine (a) whether indices of fluency related to cognitive-linguistic versus motor processing would differ between speakers with aphasia plus AOS and speakers with aphasia only and (b) whether cognitive load reduces fluency in speakers with aphasia with and without AOS.

Method: Fourteen speakers with aphasia (seven with AOS) and seven neurotypical controls retold short stories alone (single task) and while simultaneously distinguishing between a high and low tone (dual task). Their narrative samples were analyzed for speech fluency according to sample duration, speech rate, pause/fill time, and repetitions per syllable.

Results: As expected, both speaker groups with aphasia spoke slower and with more pauses than the neurotypical controls. The speakers with AOS produced more repetitions and longer samples than controls, but they did not differ on these measures from the speakers with aphasia without AOS. Relative to the single task condition, the dual task condition increased the duration of pauses and fillers for all groups, but reduced speaking rate only for the control group. Sample duration and frequency of repetitions did not change in response to cognitive load.

Conclusion: Speech output in aphasia becomes less fluent when speakers have to engage in simultaneous tasks, as is typical in everyday conversation. Although AOS may lead to more sound and syllable repetitions than normal, speaking tasks other than narrative discourse might better capture this specific type of disfluency. Future research is needed to confirm and expand these preliminary findings.
\end{abstract}




\section{Introduction}

Disfluencies - or interruptions to the flow of speech—are common in aphasia. They can be caused by a number of inefficiencies in morphosyntactic, lexical, and phonological processing as speakers struggle to find the expressions they desire and observe errors in their own output. The coexistence of apraxia of speech (AOS) may compound this disfluency through an added layer of inefficient motor programming or planning. In fact, reduced speech rate and abnormal prosody are considered primary diagnostic criteria for AOS (Wambaugh, Duffy, McNeil, Robin, \& Rogers, 2006). Although disfluency in AOS has been noted over previous decades (Baum, 1992; Deal \& Darley, 1972; Johns \& Darley, 1970; McNeil, Liss, Tseng, \& Kent, 1990; Trost, 1970), it has rarely been described systematically during connected speech (see Bailey, Blomgren, Delong, Fassbender, \& Wambaugh, 2017; Liss, 1998 for exceptions). In the present study, we describe speech fluency during narrative production in speakers with coexisting AOS and aphasia as well as in speakers with aphasia alone. Recognizing that fluency is determined by situational demands, we take the comparison one step further and provide preliminary observations about how cognitive demands affect fluency in these two populations.

\section{Relevance of Extended Pauses and Repetitions}

A number of behaviors are known to interfere with the forward flow of speech (e.g., extended pauses, fillers, repetitions, revisions). While the method of measurement has varied, inefficiencies in cognitive-linguistic processing have most often been linked to relatively longer (extended) pauses (Hird \& Kirsner, 2010; Mack et al., 2015; Schlenck, Huber, \& Willmes, 1987). In speakers without speech and language impairment, extended pauses are commonly defined as periods of silence that are longer than 200-300 ms (Goldman-Eisler, 1968). Measuring pauses in the discourse of people with aphasia (PWA), however, is complicated by more frequent 
and longer pausing in this group and potential confounds related to motor speech production. It is unclear what the appropriate cutoff should be, particularly in a sample of speakers with diverse aphasia presentations and speaking rates. Schlenck et al. (1987) used a 2 s pause cutoff to analyze picture descriptions from participants with stroke-induced aphasia. The authors' assumption was that pauses and filled pauses longer than this value would reflect "linguistic trouble" (p. 233). In contrast, Mack et al. (2015) examined narrative discourse samples produced by participants with primary progressive aphasia and defined pauses longer than $300 \mathrm{~ms}$ as extended. With this approach, they observed more frequent pauses in the agrammatic variant, which by definition included participants with motor planning deficits. It is also worth noting that between-word discourse pauses in the $150-750 \mathrm{~ms}$ range have been considered characteristic of childhood and acquired apraxia of speech (Shriberg et al., 2017a, 2017b). Some authors have taken an empirical approach to the categorization, distinguishing between "short" and "extended" pauses on an individual basis by splitting pauses into two groupings based on the observation of bimodal within-speaker pause distributions (e.g., Angelopoulou et al., 2018; Hird \& Kirsner, 2010). Using this method, Angelopoulou et al. (2018) analyzed speech samples that were elicited from responses to open-ended interview questions about personal history. They found that the median length of extended pauses was significantly greater for 18 PWA (785 ms) than 19 neurotypical controls $(670 \mathrm{~ms})$. Other studies have reported similar values for neurotypical speakers' pause duration during interviews $(530 \mathrm{~ms})$, but longer pausing during story retell tasks (940 ms; Kowal, Wiese, \& O’Connell, 1983). Thus, discourse type must also be taken into consideration defining what pause duration should be considered "extended."

Whereas extended pauses have been linked to cognitive-linguistic processing, problems related to motor speech might be reflected in speaker-initiated repetitions of sounds and 
syllables, which are one form of stutter-like disfluency (Conture, 2001; Goberman, Blomgren, \& Metzger, 2010; Watkins, Smith, Davis, \& Howell, 2008). Because these repetitions are analyzed at the level of sounds and syllables instead of words, they have been considered motoric rather than linguistic in nature. Based on this reasoning, Bailey and colleagues (2017) identified stutterlike disfluencies in discourse samples from 20 participants with aphasia and AOS. They used the Lidcombe Behavioral Data Language to code both fixed postures (i.e., transient cessation of articulatory movement during speech) and repeated movements (i.e., sound, syllable, and multisyllabic unit repetitions; see also Teesson, Packman, \& Onslow, 2003). Repeated movements were observed in 3.5 percent of word s during discourse and accounted for almost all stutter-like disfluencies (88\%). Although the authors suggested that many participants with AOS produced an abnormally high proportion of repetitions due to their impaired motor planning or programming, they included no comparison or control group.

\section{Effects of Cognitive Demands}

Extended pauses and repetitions are not unique to aphasia or AOS, but also occur in neurotypical adults, and may increase in frequency when the speaker performs two tasks concurrently. For example, neurotypical adults have been shown to speak more slowly and produce more fillers or filled pauses when simultaneously talking and finger tapping, ignoring noise, or performing a tactile-form recognition task than when talking only (Kemper, Herman, \& Lian, 2003; Oomen \& Postma, 2001). PWA are not immune to the attentional cost and have also been shown to decrease speech rate and increase pausing when their attention is divided between two tasks (Harmon, 2018; Murray, Holland, \& Beeson, 1998).

It is less clear how cognitive load may affect repetitions. Oomen and Postma (2001) found that undergraduate students produced more sound and part word repetitions when telling a 
story and simultaneously exploring sandpaper figures tactilely than when telling a story without a concurrent task. In contrast, Eichorn and colleagues recently reported that both people who do and do not stutter produced fewer stutter-like disfluencies while talking and simultaneously performing verbal and spatial working memory tasks (Eichorn, Marton, Schwartz, Melara, \& Pirutinsky, 2016). Their measure of stutter-like disfluencies consisted mainly of repetitions (i.e., sound, syllable, and monosyllabic word repetitions) but also included prolongations and blocks. Different demands of the secondary task may have contributed to the contrasting results of these two studies. For instance, the working memory dual task may have been more demanding than the sandpaper exploration because it required continuous processing of novel information. Eichorn and colleagues (2016) suggested that people who stutter reduced stutter-like disfluencies in the dual task condition because it facilitated automatization by drawing away internal attention to motor control (see also Wulf, McNevin, \& Shea, 2001).

Similar to the internal attention account, overreliance on auditory feedback might disrupt automatization by causing speakers with AOS to focus internally on acoustic or movement patterns of their speech (Jacks, 2008; Maas et al., 2008). Restricting access to auditory feedback with continuous masking noise might decrease disfluencies in AOS by causing speakers to attend less to their errors (Jacks \& Haley, 2015). Similarly, distracting people from conscious control of their speech through a dual task might also redirect attentional resources from internal focus on feedback. It is possible, therefore, that dual task conditions could cause people with AOS to revert to residual feedforward control processes and that this, in turn, may reduce disfluency.

To our knowledge, disfluency types have not been previously characterized and compared between PWA with and without AOS. The first aim of this study was to provide a preliminary examination of extended and filled pauses (greater than $1 \mathrm{~s}$ ) as well as repetitions in 
these groups during a story retell procedure. Because of their association with cognitivelinguistic processing, we hypothesized more extended pauses in samples from PWA than neurotypical controls but no distinction in this measure between PWA with and without cooccurring AOS. On the other hand, given the presumed association between repetitions and motor speech impairment, we predicted that speakers with co-occurring AOS would produce more repetitions than those with aphasia uncomplicated by AOS. A second aim was to identify the effects of divided attention on speech fluency for PWA with and without AOS. In line with previous research, we predicted that divided attention would reduce speech fluency for all groups in terms of speech rate and pausing. Conversely, we hypothesized that divided attention might decrease repetitions for people with AOS by increasing automatization and/or restricting access to impaired feedback control. Clinically, findings from this study could help identify disfluency types that may be more common in people with aphasia and AOS than those with aphasia alone. In addition, because everyday communication most often occurs in situations where attentional demands are great, this study could help us glimpse how everyday communication might affect speech fluency.

\section{Method}

\section{Participants}

The present study used a subset of data collected for a larger project (Harmon, 2018). Speech and language assessments for PWA included the Western Aphasia Battery-Revised (WAB-R; Kertesz, 2006), Test of Nonverbal Intelligence-fourth edition (TONI-IV; Brown, Sherbenou, \& Johnson, 2010), the Chapel Hill Multilingual Intelligibility Test for monosyllabic words in English (CHMIT-e; Haley, Roth, Grind staff, \& Jacks, 2011), and a motor speech evaluation (MSE; Haley, Jacks, de Riesthal, Abou-Khalil, \& Roth, 2012; Wertz, LaPointe, \& 
Rosenbek, 1984). The study was approved by the UNC-CH Institutional Review Board and all participants agreed to the study procedures by signing an informed consent form.

Results from the MSE were used to diagnose AOS and dysarthria. PWA were excluded if they (a) had not completed a recent MSE, (b) were judged to have dysarthria, or (c) scored in the normal range on the WAB-R (AQ > 93.8) and displayed no characteristics of AOS.

Differentiation between AOS and aphasia (APH) was based on a combination of acoustic and perceptual strategies. The primary acoustic criterion was word syllable duration (WSD). This accounted for the average duration (in seconds) of each syllable during production of 10 multisyllabic words from the MSE (e.g., harmonica, stethoscope, constitution, jabbering). WSD has high inter-observer reliability (Haley et al., 2012) and has previously been used as a grouping strategy for AOS (Haley, Jacks, \& Cunningham, 2013; Haley, Jacks, Richard son, \& Wambaugh, 2017). The primary perceptual features observed were prominent distortion and distorted substitution errors as judged subjectively by the three authors. Seven participants with WSD greater than $330 \mathrm{~ms}$ and subjectively salient sound distortion errors were classified as having AOS (Haley et al., 2017). Seven additional participants demonstrated subjectively infrequent sound distortions and WSD shorter than $330 \mathrm{~ms}$ and were, therefore, classified as APH. Mean WSD was 412.10 for the AOS group and 276.05 for the APH group.

Table 1 shows demographic information for the three participant groups and individual scores from speech and language testing are provided in Table 2. Participants from both AOS and APH groups were more than 1-year post-onset and were relatively comparable on WAB-R and TONI-IV scores. The AOS group included four females and three males with an average WAB-R aphasia quotient $(\mathrm{AQ})$ of $72.03(S D=13.42$; range $=52.1-97.4)$ and mean TONI-IV score of $99.71(S D=6.65$; range $=90-105)$. The APH group included 5 females and two males 
with an average WAB-R AQ of $77.81(S D=9.97$; range $=63.7-89.9)$ and mean TONI-IV score was $96.57(S D=10.18$; range $=88-119)$. The control group included four females and three males. All participants passed a hearing screening at $40 \mathrm{~dB}$ for $0.5,1$, and $2 \mathrm{kHz}$ or - in the case of one whose hearing was not tested - reported normal hearing. They also passed a vision screening.

\section{Procedures}

Participants retold one short story without a concurrent task (single task condition) and another while simultaneously discriminating between two tones (dual task condition). Story stimuli were matched for content (i.e., number of words, number of sentences, number of subordinate clauses and mean sentence length) and complexity (i.e., ratio of clauses to T-units, listening difficulty, and number of unfamiliar words), and were designed to assess narrative production in aphasia (Doyle et al., 1998). In a sound field over PC speakers and monitor, participants were presented with both auditory information (i.e., an audio recording of a male speaker telling the story) and visual support (i.e., six pictures that went along with the story), then asked to retell the story without visual or auditory stimuli. Each participant practiced the task by telling one story to the investigator before beginning the experiment. During the practice story, the investigator verified that the presentation volume was adequate for the participant and adjusted as needed. The stories were pseudorandomly assigned across conditions.

In the single task condition, participants were instructed to retell the story as best they could to a student volunteer who sat across the table from them. When necessary, the student provided minimum cueing to stay on task (e.g., "What happened next?" "Just do the best you can.”). In the dual task condition, participants were asked to retell the story to the same student volunteer but this time simultaneously discriminate between two tones by pushing a red button 
when they heard a high tone $(2000 \mathrm{~Hz})$ and a blue button when they heard a low tone $(500 \mathrm{~Hz})$. Tones were presented in a sound field over PC speakers with the volume adjusted to approximately the same level for all participants. The timing of tone presentations was pseudorandomized at an average interval of six seconds (range $=2-8 \mathrm{~s}$ ). Prior to the dual task condition, participants practiced identifying tones in isolation for approximately two minutes to ensure they understood the task and to obtain baseline measures of accuracy and reaction time. Tones were presented and discrimination accuracy and reaction times were automatedly tracked using a custom Matlab script.

The primary dependent variables of interest were four measures of speech fluency: total sample duration, speech rate, extended pause/fill time, and repetitions. Speech rate was calculated as the number of syllables produced per second. Syllable counts were obtained by using a click-counter while listening to the recorded speech samples (see Ingham \& Ingham, 2011 for a similar method used in the stuttering literature). Extended pause/fill time accounted for the percentage of time per sample taken up by (a) silent pauses greater than one second, (b) fillers (i.e., "um," or "uh"), and (c) filled pauses (i.e., pauses that were only broken up by filler words) greater than one second. This was done by manually marking any pause or filled pause that exceeded one second from the offset of the last speech segment prior to pausing to the onset of the first segment after pausing. We selected a $1 \mathrm{~s}$ cutoff to account for longer than average pausing during a story retell task for neurotypical speakers (Kowal et al., 1983), and avoid confounds related to motor speech impairment (Shriberg et al., 2017a, 2017b). Repetitions accounted for the percentage of repeated syllables. This measure was calculated by dividing the number of simple repetitions (e.g., sound, syllable, and monosyllabic word repetitions with no other intervening speech sounds) produced per sample by the total number of syllables, 
multiplied by 100. Extended pauses, filled pauses, fillers, and repetitions were marked using Praat (Boersma \& Weenink, 2014). The first author and a graduate student research assistant each coded half of the samples. Intrarater reliability for each coder was high for both pause/fill time and repetitions per syllable $(r=.99)$. Interrater reliability was also high (pause/fill time, $r=$ .98 ; repetitions, $r=.94)$. To provide some information about content, samples were transcribed and all intelligible words except fillers and phonological fragments were automatedly counted using the computerized language analysis (CLAN) software (MacWhinney, 2000).

Secondary dependent variables included tone discrimination accuracy and response time. Tone discrimination accuracy was measured as the proportion of tones that the participant identified accurately by pushing the correct button. Tone discrimination response time was calculated as the time in seconds between tone presentation and button press response. The average accuracy and response time in each condition across the three participant groups are reported in online Supplemental Table S1.

\section{Statistical Analysis}

Data for all primary dependent variables (i.e., sample duration, rate, pause/fill time, and repetitions) were distributed normally and, therefore, analyzed using two-way mixed effects ANOVAs. This was also the analysis method for the secondary dependent variable of tone discrimination response time, which showed a normal distribution. The between subject variable was "Group" (i.e., AOS, APH, control). The within subject variable was "Condition" (i.e., single task, dual task). Significant main and interaction effects were followed with Tukey's HSD using a familywise error rate of .05 . Because tone discrimination accuracy data did not follow a normal distribution, this variable was analyzed using Kruskal-Wallis tests. 
Statistical analyses were completed using R 3.4.1 (R Core Team, 2017). Mixed-effects ANOVAs were completed on models built using the lme function within the nlme package (Pinheiro, Bates, Debroy, Sarkar, \& R Core Team, 2017) and pairwise comparisons were made on the model using the emmeans package (Lenth, 2017).

\section{Results}

All participants with aphasia spoke more slowly and spent more time pausing and using fillers than the neurotypical speakers. In addition, the AOS group produced significantly longer samples than the control group, which also contained more repetitions (See Figure 1). Sample content, in terms of intelligible words produced, was comparable between and within groups showing no main or interaction effects (see Online Supplemental Table S2). A significant Group effect was found for sample duration $(p=.008)$, which was explained by story retell samples being longer for the AOS than the control group $(p=.006)$. There was no difference in sample duration between the APH and AOS group $(p=.163)$ or the APH and control group $(p=.240)$ and no condition or interaction effects. Speech rate results showed a significant Group X Condition interaction $(F[2,18]=3.71, p=.045)$. AOS and APH groups both had a slower speaking rate than controls $(p<.001)$, but did not differ significantly from each other. While speech rate was reduced for all groups in the dual task condition, the change was only significant for the control group $(p<.001)$. Inspection of individual data revealed that all participants except two $(\mathrm{P} 11, \mathrm{C} 07)$ reduced their speech rate in the dual task condition but the magnitude of change was generally greater for the control group than the AOS and APH groups (see Table 3).

Pause/fill time was greater for APH and AOS groups than the control group. Results showed a significant main effect for Group $(F[2,18]=10.63, p<.001)$, which was explained by significant differences between control and AOS $(p=.002)$ and control and APH $(p=.002)$ 
groups, whereas there was no difference between AOS and APH groups $(p=.999)$. In the dual task condition, time spent in pauses and fillers increased as revealed by a main effect of Condition $(F[2,18]=32.85, p<.001)$. Individually, time spent pausing was greater in the dual task condition for all participants except two (P03, P11).

The repetition results showed a significant main effect for Group $(F[2,18]=5.83, p=$ .011), which was explained by participants with AOS producing significantly more repetitions than controls $(p=.008)$. Again, there was no significant difference in repetitions between AOS and APH groups $(p=.284)$. No significant dual task effect was found for repetitions $(F[2,18]=$

$0.89, p=.358$ ). The APH group reduced their repetitions on average during the dual task, but this was not statistically significant. Individual data showed that four of seven participants from the AOS group increased repetitions in the dual task condition. In contrast, all participants except one from the APH group (P10) reduced their repetitions in the dual task condition.

Tone discrimination accuracy and response time did not differ among the participant groups but did change during the dual task condition. Results showed a main effect of condition for both accuracy $(H(2)=13.37, p<.001)$ and response time $(F[2,18]=25.67, p<.001)$ revealing that participants reduced their accuracy and increased their response time on the tone discrimination task; no effect was found for group or interaction.

\section{Discussion}

The first aim of the present study was to characterize the presentation of disfluencies (particularly pause/fill time and repetitions) produced by people with and without AOS during connected speech. While the connected speech of PWA was slower and had greater pause/fill time than controls, only the AOS group produced longer samples with significantly more repetitions. The second aim was to investigate the effects of divided attention on speech fluency. 
Generally, participants reduced their fluency while retelling stories in a dual task condition, but the magnitude of the reductions varied among groups.

Results from this study expand research linking extended pauses to cognitive-linguistic processing in aphasia. Recent reports have shown that PWA produce more and longer extended pauses than controls (Angelopoulou et al., 2018; Hird \& Kirsner, 2010). Similarly, we found that a greater percentage of narrative samples were taken up by extended pauses and fillers for PWA. It was striking that pauses and fillers took up nearly half of the sample (and sometimes more) for most AOS and APH participants, which was much larger than the proportion taken up by these behaviors in the samples of neurotypical controls. Increased cognitive demands via a dual task also increased pause/fill time for all participants, but the speech rate reduction was statistically significant only for the control group. The lack of effect for participants with aphasia may have been influenced by their already slow rate at baseline. It is likely that the story retell task was linguistically and cognitively demanding for these groups even before the secondary task was added, causing them to approach it more deliberately and with limited room to alter their strategy.

To explore the link between sample duration, speech rate, pause/fill time, and aphasia severity, we performed a post-hoc correlational analysis. For participants with aphasia, there was a moderate positive correlation between WAB-R AQ and speech rate $(r=.480, p=.009)$ and a weak negative correlation between WAB-R AQ and pause/fill time $(r=-.344, p=.073)$, suggesting that both measures might relate to language severity. Unlike speech rate and pause/fill time, repetitions and sample duration showed no relationship with severity of language impairment. 
Our findings regarding repetitions support the suggestion by Bailey and colleagues (2017) that people with AOS produce an abnormally high proportion of repetitions during connected speech, but are inconclusive as to whether repetition frequency can distinguish between aphasia with and without AOS. If, as previously suggested, repetitions are motoric in origin (see e.g., Bailey et al., 2017; Conture, 2001), we would suspect higher proportion of this type of disfluency in AOS than in aphasia without AOS. This was not the case in the present study but our sample size was small and participants with aphasia showed high variability in their repetitions. Specifically, the raw frequency of repetitions for PWA was relatively low $(M=$ 4) but had a wide range ( 0 to 19$)$. The type of sample may have contributed to this variability. Because the narrative samples did not constrain speech to specific targets, some participants may have avoided difficult articulatory movements via circumlocution, potentially reducing their repetition frequency. Comparing our findings with previous research, it seems that a naming task might lead to a greater proportion of repetitions than repeated words and connected speech (Bailey et al., 2017; Trost, 1970). Repetitions in naming, therefore, might provide better data for comparison between APH and AOS groups and should be investigated in future work.

Connected speech, nonetheless, represents the most ecologically valid sample type and affects how people with AOS are perceived by naïve listeners (Harmon, Jacks, Haley, \& Faldowski, 2016) and jud ged by clinicians (Penttilä et al., 2018).

Although there were no statistically significant dual task effects on repetitions, we observed an interesting pattern in the individual data. Contrary to our hypothesis, participants with AOS were more likely to increase rather than reduce their repetitions when engaging in dual tasks and all but one participant from the APH group reduced their repetitions in the dual task condition. Given the preliminary nature of this study, future research is needed to determine 
whether this pattern holds across a larger group of participants. It is possible that, rather than force automatization or greater reliance on the feedforward system, the increased effort required in the cognitively demanding dual task condition caused participants with AOS to work harder to attend to their speech. Perhaps this condition did not have the same effect on the APH group because they produce relatively few sound errors and are more easily drawn away from internal attention to speech. In addition to testing these results in a larger sample, future research should consider different types of secondary tasks that rely on different cognitive or perceptual systems (e.g., working memory, visual tracking).

Often, when speech fluency during connected speech is measured in aphasia and AOS, disfluency types are not considered or are subsumed in an omnibus "error" measure. For example, recent treatment and neuroimaging studies have defined speech fluency based only on measures of rate (Lee, Kaye, \& Cherney, 2009; van der Meulen, van de Sandt-Koenderman, \& Ribbers, 2012; Wang et al., 2013; Youmans, Youmans, \& Hancock, 2011). Other studies have grouped pauses, fillers, and repetitions with other errors to account for word finding difficulties (Boyle, 2014) or articulation problems (Southwood, 1987). Based on the present findings, we suggest that measures of rate during connected speech can account for improvements in cognitive-linguistic processing in aphasia but might overlook changes in fluency related to motor control. Because speech fluency in aphasia is multifaceted (Feyereisen, Pillon, \& de Partz, 1991; Penttilä et al., 2018), considering both the rate of speech and different behaviors that interrupt the flow of speech (e.g., pausing and repetitions) could better specify changes in speech and language production during connected speech.

\section{Limitations and Future Directions}


Findings from this preliminary study should be considered in light of sample size and variables measured. First, the number of participants in each of our groups was small (i.e., seven). There was also high intra-group variability for some of the measures. Future research is needed to confirm these preliminary findings with larger groups. Second, not all possible variables and measurement techniques related to speech fluency were considered. For example, we used speech rate (calculated using sample duration) instead of articulation rate (calculated using speaking time). While it is possible that articulation rate would have shown differences between AOS and APH groups, this is unlikely given the similarly high pause/fill time in both groups. We also did not code revisions, which is another common type of disfluency in aphasia and AOS (McNeil, Odell, Miller, \& Hunter, 1995; Trost, 1970). Finally, we measured extended pauses but did not account for short pauses. We defined extended pauses as those greater than one second to account for longer than normal pausing during story retell (Kowal et al., 1983). Because our study included participants with motor speech impairment, we thought that a shorter cutoff might confound this measure by including short within-sentence pauses that reflect motor planning (see Mack et al., 2015, p. 219 for a discussion of this possibility). Short pauses, however, could provide important information about speech production (Hird \& Kirsner, 2010) and might be more prevalent in AOS (see e.g., Shriberg et al., 2017a, 2017b). Future research should compare both short and long pauses in PWA with and without co-occurring AOS.

Despite these limitations, this preliminary study sets the stage for future research investigating specific disfluency types in aphasia and AOS. This is also the first study that we know of to apply dual task conditions to speakers with AOS. Over the past decades, the speech of people with AOS has frequently been described as "effortful” (see McNeil, Ballard, Duffy, \& Wambaugh, 2017 for a review). Qualitative evidence also supports that talking requires great 
effort and attention for people with AOS (e.g., Haley, Shafer, Harmon, \& Jacks, 2016). Future research is needed to further investigate the role of attention on speech production in AOS.

\section{Conclusions}

People with aphasia generally speak less fluently than neurotypical controls. Like neurotypical controls, though, they reduce their speech fluency as cognitive demands of the communication situation increase. Sound and syllable repetitions might be more prevalent in AOS than normal speakers but other speech tasks may capture this disfluency better than narrative discourse. Future research is needed to confirm preliminary findings from the present study and explore additional tasks and measures that capture disfluent behaviors specific to AOS. Future research should also further consider how attention to speech affects production in AOS.

Acknowledgments: This research was supported by a Dissertation Completion Fellowship Award provided by the University of North Carolina at Chapel Hill Graduate School. Special thanks to Morgan Billinger, Tayler Simonds, Matthew Suderman, Lena Wedeen, Marissa Rock, and Laura Blizard who assisted with data collection and coding. 


\section{References}

Angelopoulou, G., Kasselimis, D., Makrydakis, G., Varkanitsa, M., Roussos, P., Goutsos, D., ... Potagas, C. (2018). Silent pauses in aphasia. Neuropsychologia, 114, 41-49.

http://d oi.org/10.1016/j.neuropsychologia.2018.04.006

Bailey, D. J., Blomgren, M., Delong, C., Fassbender, K., \& Wambaugh, J. L. (2017). Quantification and systematic characterization of stuttering-Like disfluencies in acquired apraxia of speech. American Journal of Speech-Langauge Pathology, 26, 641-648. http://doi.org/10.1044/2017_AJSLP-16-0108

Baum, S. R. (1992). The influence of word length on syllable duration in aphasia: Acoustic analyses. Aphasiology, 6(5), 501-513. http://doi.org/10.1080/02687039208249487

Boersma, P., \& Weenink, D. (2014). Praat: Doing phonetics by computer. Retrieved from http://www.praat.org/

Boyle, M. (2014). Test-retest stability of word retrieval in aphasic discourse. Journal of Speech, Language and Hearing Research, 57, 966-978. http://doi.org/10.1044/2014_JSLHR-L-130171

Brown, L., Sherbenou, R. J., \& Johnson, S. K. (2010). Test of Nonverbal Intelligence, Fourth Edition. San Antonio, TX: Pearson.

Conture, E. (2001). Stuttering: Its nature, diagnosis, and treatment. Boston, MA: Allyn \& Bacon.

Deal, J. L., \& Darley, F. L. (1972). The influence of linguistic and situational variables on phonemic accuracy in apraxia of speech. Journal of Speech, Language, and Hearing Research, 15, 639-653. http://doi.org/10.1044/jshr.1503.639

Eichorn, N., Marton, K., Schwartz, R. G., Melara, R. D., \& Pirutinsky, S. (2016). Does working memory enhance or interfere with speech fluency in adults who do and do not stutter? Evidence from a dual-task paradigm. Journal of Speech, Language, and Hearing Research, 59, 415-429. http://doi.org/10.1044/2015

Feyereisen, P., Pillon, A., \& de Partz, M.-P. (1991). On the measures of fluency in the assessment of spontaneous speech production by aphasic subjects. Aphasiology, 5(1), 1-21. http://d oi.org/10.1080/02687039108248516

Goberman, A. M., Blomgren, M., \& Metzger, E. (2010). Characteristics of speech disfluency in Parkinson disease. Journal of Neurolinguistics, 23(5), 470-478. http://d oi.org/10.1016/j.jneuroling.2008.11.001

Goldman-Eisler, F., 1968. Psycholinguistics: Experiments in Spontaneous Speech. Academic Press, New York.

Green, J. R., Beukelman, D. R., \& Ball, L. J. (2004). Algorithmic estimation of pauses in 
extended speech samples of dysarthric and typical speech. Journal of Medical SpeechLanguage Pathology, 12(4), 149-154.

Haley, K. L., Jacks, A., \& Cunningham, K. T. (2013). Error variability and the differentiation between apraxia of speech and aphasia with phonemic paraphasia. Journal of Speech, Language, and Hearing Research, 56(3), 891-905. http://doi.org/10.1044/10924388(2012/12-0161)

Haley, K. L., Jacks, A., de Riesthal, M., Abou-Khalil, R., \& Roth, H. L. (2012). Toward a quantitative basis for assessment and diagnosis of apraxia of speech. Journal of Speech, Language, and Hearing Research, 55, 1502-1517. http://doi.org/10.1044/10924388(2012/11-0318)b

Haley, K. L., Jacks, A., Richard son, J. D., \& Wambaugh, J. L. (2017). Perceptually salient sound distortions and apraxia of speech: A performance continuum. American Journal of SpeechLanguage Pathology, 26, 631-640. http://doi.org/10.1044/2017_AJSLP-16-0103

Haley, K. L., Roth, H., Grindstaff, E., \& Jacks, A. (2011). Computer-mediated assessment of intelligibility in aphasia and apraxia of speech. Aphasiology, 25(12), 1600-1620. http://d oi.org/10.1080/02687038.2011.628379

Haley, K. L., Shafer, J. N., Harmon, T. G., \& Jacks, A. (2016). Recovering with acquired apraxia of speech: The first 2 years. American Journal of Speech-Langauge Pathology, 25(December), S687-S696. http://doi.org/10.1044/2016

Harmon, T. G. (2018). Communication partner attitudes, social and cognitive challenge, and spoken language in aphasia (Doctoral dissertation). University of North Carolina at Chapel Hill. Retrieved from https://search.proquest.com/docview/2056936531 accountid=4488

Harmon, T. G., Jacks, A., Haley, K. L., \& Faldowski, R. A. (2016). Listener perceptions of simulated fluent speech in nonfluent aphasia. Aphasiology, 30(8), 922-942. http://d oi.org/10.1080/02687038.2015.1077925

Hird, K., \& Kirsner, K. (2010). Objective measurement of fluency in natural language production: A dynamic systems approach. Journal of Neurolinguistics, 23(5), 518-530. http://d oi.org/10.1016/j.jneuroling.2010.03.001

Ingham, J. C., \& Ingham, R. J. (2011). The Stuttering Measurement System (SMS) Training Manual.

Jacks, A. (2008). Bite block vowel production in apraxia of speech. Journal of Speech, Language, and Hearing Research, 51(4), 898-913. http://doi.org/10.1044/10924388(2008/066)

Jacks, A., \& Haley, K. L. (2015). Auditory masking effects on speech fluency in apraxia of speech and aphasia: Comparison to altered auditory feed back. Journal of Speech, Language and Hearing Research, 58(December), 1670-1686. http://doi.org/10.1044/2015_JSLHR-S$14-0277$ 
Johns, D. F., \& Darley, F. L. (1970). Phonemic variability of speech. Journal of Speech, Language \& Hearing Research, 13, 556-583. http://doi.org/10.1044/jshr.1303.556

Kemper, S., Herman, R. E., \& Lian, C. H. T. (2003). The costs of doing two things at once for young and older adults: Talking while walking, finger tapping, and ignoring speech or noise. Psychology and Aging, 18(2), 181-192. http://doi.org/10.1037/0882-7974.18.2.181

Kertesz, A. (2006). Western Aphasia Battery-Revised (WAB-R). San Antonio, TX: Pearson. Retrieved from http://www.asha.org/SLP/assessment/Western-Aphasia-Battery-Revised(WAB-R).htm

Kowal, S., Wiese, R., \& O'Connell, D. C. (1983). The use of time in storytelling. Language and Speech, 26(4), 377-392.

Lee, J. B., Kaye, R. C., \& Cherney, L. R. (2009). Conversational script performance in adults with non-fluent aphasia: Treatment intensity and aphasia severity. Aphasiology, 23(7-8), 885-897. http://doi.org/10.1080/02687030802669534

Lenth, R. (2017). emmeans: Estimated Marginal Means, aka Least-Squares Means. Retrieved from https://CRAN.R-project.org/package=emmeans

Liss, J. M. (1998). Error-revision in the spontaneous speech of apraxic speakers. Brain and Language, 62(3), 342-60. http://doi.org/10.1006/brln.1997.1907

Mack, J. E., Chandler, S. D., Meltzer-Asscher, A., Rogalski, E., Weintraub, S., Mesulam, M. M., \& Thompson, C. K. (2015). What do pauses in narrative production reveal about the nature of word retrieval deficits in PPA? Neuropsychologia, 77(3), 211-222.

http://d oi.org/10.1016/j.neuropsychologia.2015.08.019

Maas, E., Robin, D. A., Austermann Hula, S. N., Freedman, S. E., Wulf, G., Ballard, K. J., \& Schmidt, R. A. (2008). Principles of motor learning in treatment of motor speech disorders. American Journal of Speech-Language Pathology, 17(3), 277-98. http://d oi.org/10.1044/1058-0360(2008/025)

MacWhinney, B. (2000). The CHILDES Project: Tools for Analyzing Talk (3rd ed.). Mahway, NJ: Lawrence Erlbaum Associates.

Mcneil, M. R., Ballard, K. J., Duffy, J. R., \& Wambaugh, J. (2017). Apraxia of speech theory, assessment, differential diagnosis, and treatment: Past, present, and future. In Speech Motor Control in Normal and Disordered Speech (pp. 195-222). American Speech-LanguageHearing Association.

McNeil, M. R., Liss, J. M., Tseng, C. H., \& Kent, R. D. (1990). Effects of speech rate on the absolute and relative timing of apraxic and conduction aphasic sentence production. Brain and Language, 38, 135-158. http://doi.org/10.1016/0093-934X(90)90106-Q

McNeil, M. R., Odell, K. H., Miller, S. B., \& Hunter, L. (1995). Consistency, variability, and 
target approximation for successive speech repetitions among apraxic, conduction aphasic, and ataxic dysarthric speakers. Clinical Aphasiology.

Murray, L. L., Holland, A. L., \& Beeson, P. M. (1998). Spoken language of individuals with mild fluent aphasia under focused and divided-attention conditions. Journal of Speech Language and Hearing Research, 41(1), 213-227.

Nickels, L., \& Howard, D. (1995). Phonological errors in aphasic naming: Comprehension, monitoring and lexicality. Cortex, 31(2), 209-237. http://doi.org/10.1016/S00109452(13)80360-7

Oomen, C. C., \& Postma, A. (2001). Effects of divided attention on the production of filled pauses and repetitions. Journal of Speech, Language, and Hearing Research, 44(5), 997 1004. http://d oi.org/10.1044/1092-4388(2001/078)

Peach, R. K., \& Coelho, C. A. (2016). Linking inter- and intra-sentential processes for narrative production following traumatic brain injury: Implications for a model of discourse processing. Neuropsychologia, 80, 157-164.

http://doi.org/10.1016/j.neuropsychologia.2015.11.015

Penttilä, N., Korpijaakko-Huuhka, A., \& Kant, R. D. (2018). Auditory - Perceptual Assessment of Fluency in Typical and Neurologically Disordered Speech. Journal of Speech, Language \& Hearing Research, 61, 1086-1103. http://doi.org/10.1044/2018_JSLHR-S-17-0326

Pinheiro, J., Bates, D., Debroy, S., Sarkar, D., \& R Core Team (2017). nlme: Linear and nonlinear mixed effects models. Retrieved from https://cran.r-project.org/package=nlme

R Core Team (2017). R: A language and environment for statistical computing. Vienna, Austria: R Foundation for Statistical Computing. Retrieved from http://www.r-project.org/

Schlenck, K. J., Huber, W., \& Willmes, K. (1987). "Prepairs" and repairs: Different monitoring functions in aphasic language production. Brain and Language, 30(2), 226-244. http://d oi.org/10.1016/0093-934X(87)90100-3

Shriberg, L. D., Strand, E. A., Fourakis, M., Jakielski, K. J., Hall, S. D., Karlsson, H. B., ... Wilson, D. L. (2017a). A diagnostic marker to discriminate childhood apraxia of speech from speech delay: I. Development and description of the pause marker. Journal of Speech Language and Hearing Research, 60(4), S1096-S1117. http://doi.org/10.1044/2016_JSLHR-S-15-0296

Shriberg, L. D., Strand, E. A., Fourakis, M., Jakielski, K. J., Hall, S. D., Karlsson, H. B., ... Wilson, D. L. (2017b). A diagnostic marker to discriminate childhood apraxia of speech from speech delay: II. Validity studies of the pause marker index. Journal of Speech Language and Hearing Research, 60(4), S1118-S1134. https://doi.org/10.1044/2016_JSLHR-S-15-0297

Southwood, H. (1987). The use of prolonged speech in the treatment of apraxia of speech. In 
Clinical Aphasiology Conference (pp. 277-287). BRK Publishers.

Teesson, K., Packman, A., \& Onslow, M. (2003). The Lidcombe Behavioral Data Language of stuttering. Journal of Speech, Language \& Hearing Research, 46(August 2003), 10091015. http://doi.org/10.1044/1092-4388(2003/078)

Trost, J. E. (1970). A descriptive study of verbal apraxia in patients with Broca's aphasia (Doctoral dissertation). Northwestern University.

van der Meulen, I., van de Sandt-Koenderman, M. E., \& Ribbers, G. M. (2012). Melodic Intonation Therapy: Present controversies and future opportunities. Archives of Physical Medicine and Rehabilitation, 93, S46-52. http://doi.org/10.1016/j.apmr.2011.05.029

Wambaugh, J. L., Duffy, J. R., McNeil, M. R., Robin, D. A., \& Rogers, M. A. (2006). Treatment guidelines for acquired apraxia of speech: Treatment descriptions and recommendations. Journal of Medical Speech-Language Pathology, 14(2), xv-xxxii.

Wang, C., Marchina, S., Norton, A. C., Wang, J., Wan, C. Y., Schlaug, G., ... Marcotte, K. (2013). Predicting speech fluency and naming abilities in aphasic patients. Frontiers in Human Neuroscience, 7(1). http://doi.org/10.3389/fnhum.2013.00831

Watkins, K. E., Smith, S. M., Davis, S., \& Howell, P. (2008). Structural and functional abnormalities of the motor system in developmental stuttering. Brain, 131, 50-59. http://doi.org/10.1093/brain/awm241

Wertz, R. T., LaPointe, L. L., \& Rosenbek, J. C. (1984). Apraxia of speech in adults: The disorder and its management. San Diego, CA: Singular.

Wulf, G., McNevin, N., \& Shea, C. H. (2001). The automaticity of complex motor skill learning as a function of attentional focus. The Quarterly Journal of Experimental Psychology, 54(4), 1143-1154. http://doi.org/10.1080/713756012

Youmans, G. L., Youmans, S. R., \& Hancock, A. B. (2011). Script training treatment for adults with apraxia of speech. American Journal of Speech-Language Pathology, 20(1), 23-37. http://doi.org/10.1044/1058-0360(2010/09-0085) 
Table 1. Group demographicinformation

\begin{tabular}{|c|c|c|c|c|c|c|c|c|c|}
\hline & \multicolumn{3}{|c|}{ AOS } & \multicolumn{3}{|c|}{$\mathrm{APH}$} & \multicolumn{3}{|c|}{ Control } \\
\hline & $M$ & $S D$ & Range & $M$ & $S D$ & Range & $M$ & $S D$ & Range \\
\hline Age (yrs) & 62.0 & 8.5 & $48-72$ & 54.7 & 11.3 & $32-65$ & 53.1 & 10.3 & $34-64$ \\
\hline Education (yrs) & 16 & 2.6 & $12-19$ & 17 & 2.6 & $13-20$ & 15 & 2.1 & $12-18$ \\
\hline TPO (yy;mm) & $7 ; 11$ & $4 ; 6$ & 1;07-12;11 & $11 ; 05$ & $4 ; 05$ & $5 ; 12-18 ; 10$ & NA & NA & NA \\
\hline
\end{tabular}

Note. TPO $=$ time post onset 
Table 2. Speech and language information from participants with aphasia

\begin{tabular}{|c|c|c|c|c|c|c|c|c|c|}
\hline \multirow[t]{2}{*}{ Participant } & \multirow[t]{2}{*}{ Group } & \multicolumn{2}{|l|}{ WAB } & \multicolumn{2}{|l|}{ TONI } & \multirow[t]{2}{*}{ WSD } & \multirow[t]{2}{*}{ Intelligibility (\%) } & \multirow[t]{2}{*}{ ClUs } & \multirow[t]{2}{*}{$\mathrm{CIUs} / \mathrm{min}$} \\
\hline & & $A Q$ & Classification & $\begin{array}{l}\text { Index } \\
\text { Score }\end{array}$ & $\begin{array}{l}\text { Descriptive } \\
\text { Term }\end{array}$ & & & & \\
\hline P04 & AOS & 72.2 & Broca's & 103 & Average & 468.22 & 37 & 13 & 3.55 \\
\hline P06 & AOS & 74.1 & Anomic & 90 & Average & 334.63 & 91 & 43 & 10.42 \\
\hline P07 & AOS & 67.5 & Broca's & 101 & Average & 395.21 & 80 & 22 & 12.52 \\
\hline P09 & AOS & 97.4 & NABW & 95 & Average & 351.78 & 88 & 207 & 80.64 \\
\hline P12 & AOS & 52.1 & Broca's & 105 & Average & 352.40 & 83 & 35 & 19.37 \\
\hline P13 & AOS & 72.7 & Broca's & 95 & Average & 602.93 & 82 & 22 & 6.76 \\
\hline P14 & AOS & 68.2 & Broca's & 109 & Average & 379.53 & 62 & 122 & 21.51 \\
\hline P01 & $\mathrm{APH}$ & 87.0 & Anomic & 92 & Average & 327.11 & 90 & 106 & 76.40 \\
\hline P02 & $\mathrm{APH}$ & 77.8 & Transcortical Motor & 95 & Average & 282.53 & 92 & 37 & 12.11 \\
\hline P03 & $\mathrm{APH}$ & 89.9 & Anomic & 88 & Below average & 259.77 & 72 & 129 & 61.06 \\
\hline P05 & $\mathrm{APH}$ & 84.3 & Anomic & 119 & Above average & 259.58 & 95 & 135 & 42.46 \\
\hline P08 & APH & 67.0 & Wernicke's & 93 & Average & 306.38 & 88 & 25 & 17.10 \\
\hline P10 & $\mathrm{APH}$ & 75.0 & Anomic & 95 & Average & 229.89 & 70 & 78 & 26.50 \\
\hline P11 & $\mathrm{APH}$ & 63.7 & Conduction & 94 & Average & 267.06 & 82 & 39 & 51.90 \\
\hline
\end{tabular}

Note. Intelligibility scores were derived from the Chapel Hill Multilingual Intelligibility Test in English (CHMIT-e; Haley, Roth, Grindstaff, \& Jacks, 2011). WAB = Western Aphasia Battery revised; $A Q=$ Aphasia Quotient; NABW = not aphasic by WAB; $T O N I=$ Test of Nonverbal Intelligence fourth edition; WSD = word syllable duration; AOS = apraxia of speech; APH = aphasia and no apraxia of speech; CIUs = correct information units 
Table 3. Individual participant data for single task (ST) and dual task (DT) story retell samples

\begin{tabular}{|c|c|c|c|c|c|c|c|c|c|c|c|}
\hline \multirow[t]{2}{*}{ ID } & \multirow[t]{2}{*}{ Group } & \multicolumn{2}{|c|}{$\begin{array}{l}\text { Word } \\
\text { Count }\end{array}$} & \multicolumn{2}{|c|}{$\begin{array}{c}\text { Sample } \\
\text { Duration (s) }\end{array}$} & \multicolumn{2}{|c|}{ Rate (syll/s) } & \multicolumn{2}{|c|}{$\begin{array}{l}\text { Pause/Fill } \\
\text { Time (\%) }\end{array}$} & \multicolumn{2}{|c|}{$\begin{array}{l}\text { Repetitions } \\
\text { (\% syllables) }\end{array}$} \\
\hline & & ST & DT & ST & DT & ST & DT & ST & DT & ST & DT \\
\hline P04 & AOS & 52 & 26 & 221.49 & 173.66 & 0.59 & 0.28 & 66.71 & 79.53 & 0.78 & 0.00 \\
\hline P06 & AOS & 240 & 148 & 247.60 & 237.36 & 1.40 & 0.93 & 30.21 & 64.01 & 2.31 & 4.55 \\
\hline P07 & AOS & 108 & 59 & 105.44 & 59.30 & 1.11 & 1.01 & 19.26 & 27.37 & 0.85 & 1.67 \\
\hline P09 & AOS & 247 & 193 & 154.03 & 140.45 & 2.07 & 1.84 & 18.64 & 34.23 & 1.57 & 1.94 \\
\hline P12 & AOS & 98 & 136 & 108.43 & 182.03 & 1.17 & 0.95 & 42.49 & 54.28 & 3.94 & 2.31 \\
\hline P13 & AOS & 65 & 67 & 186.44 & 287.50 & 0.62 & 0.38 & 60.19 & 71.17 & 2.59 & 2.73 \\
\hline P14 & AOS & 335 & 336 & 340.29 & 372.05 & 1.18 & 1.16 & 35.51 & 41.18 & 4.73 & 3.94 \\
\hline P01 & $\mathrm{APH}$ & 172 & 75 & 83.24 & 46.09 & 2.57 & 2.17 & 26.50 & 35.83 & 0.47 & 0.00 \\
\hline P02 & $\mathrm{APH}$ & 108 & 54 & 183.34 & 174.12 & 0.80 & 0.50 & 55.92 & 78.16 & 2.05 & 0.00 \\
\hline P03 & $\mathrm{APH}$ & 235 & 121 & 126.76 & 71.24 & 2.13 & 2.06 & 19.72 & 16.24 & 2.96 & 1.36 \\
\hline P05 & $\mathrm{APH}$ & 210 & 217 & 190.75 & 274.62 & 1.32 & 0.94 & 40.39 & 56.36 & 1.59 & 1.56 \\
\hline P08 & $\mathrm{APH}$ & 95 & 121 & 87.72 & 133.89 & 1.53 & 1.39 & 40.60 & 60.31 & 2.24 & 1.08 \\
\hline P10 & $\mathrm{APH}$ & 115 & 113 & 176.59 & 210.44 & 1.01 & 0.88 & 53.88 & 64.59 & 0.56 & 1.08 \\
\hline P11 & $\mathrm{APH}$ & 54 & 100 & 45.08 & 92.21 & 1.57 & 1.63 & 50.37 & 49.06 & 4.23 & 2.67 \\
\hline C01 & Control & 174 & 166 & 65.90 & 63.31 & 3.64 & 3.38 & 1.60 & 2.18 & 0.42 & 0.00 \\
\hline $\mathrm{CO} 2$ & Control & 133 & 183 & 52.67 & 86.71 & 3.21 & 2.71 & 18.83 & 21.13 & 1.18 & 0.85 \\
\hline C03 & Control & 237 & 200 & 76.36 & 86.41 & 3.84 & 2.93 & 3.81 & 10.65 & 0.00 & 0.79 \\
\hline CO4 & Control & 285 & 137 & 105.53 & 56.06 & 3.42 & 3.09 & 9.51 & 19.41 & 1.39 & 1.16 \\
\hline C05 & Control & 234 & 177 & 96.35 & 100.49 & 3.30 & 2.27 & 21.92 & 34.42 & 0.00 & 0.44 \\
\hline C06 & Control & 208 & 214 & 61.13 & 85.17 & 4.24 & 3.26 & 3.65 & 19.98 & 0.00 & 1.44 \\
\hline $\mathrm{CO}$ & Control & 167 & 212 & 64.63 & 89.68 & 3.02 & 3.11 & 10.16 & 13.43 & 0.00 & 0.00 \\
\hline
\end{tabular}

Note. AOS = aphasia with apraxia of speech; APH = aphasia and no apraxia of speech 
Figure 1. Speech fluency during connected speech across participant groups. AOS = aphasia with co-occurring apraxia of speech; APH = aphasia with no co-occurring apraxia of speech; ST = single task condition; DT = dual task condition. Significant between-group differences are noted with lines. $*=p<.01, * *=p<.001$. Boxes show inter-quartile range and whiskers extend to the upper and lower quartiles. 